\title{
Probability-Based Research on Sensitivity of Saddle-Shaped Cables Suspended
}

\author{
Zhansheng Liu and Aiwu Luo
}

\begin{abstract}
Performance-based structural analysis is the main trend of the future development of engineering design; probability-based sensitivity can reflect the importance of different parameters in the structural performance-based design. Therefore based on the response surface method, the reliability analysis program has been established, within which the sensitivity analysis of different parameters, such as the prestress, cable sectional area, cable strength and elastic modulus of saddle-shaped cable suspended, was conducted. And the corresponding sensitivity coefficient has been given, which can not only be used as a reference to the design of structure, but also can check the rationality of the structure design.
\end{abstract}

Index Terms-Saddle-shaped cables suspended, main parameters, sensitivity, response surface method

\section{INTRODUCTION}

The saddle-shaped cable suspended(as shown in Fig. 1), which belongs to the whole tensioning flexible structure, can not only overcome the deficiency of current technology, but also can realize larger span and cantilever, and it is light. The probability-based design thought, based on performance, is the development trend of today's codes [1], [2], so in the analysis and design process, how to accurately judge the key parameters of the structure performance is especially important. The sensitivity coefficient can provide a reference for the structure design, as well as check the rationality of the structure design, finally giving out the amendment opinions before construction to save money.

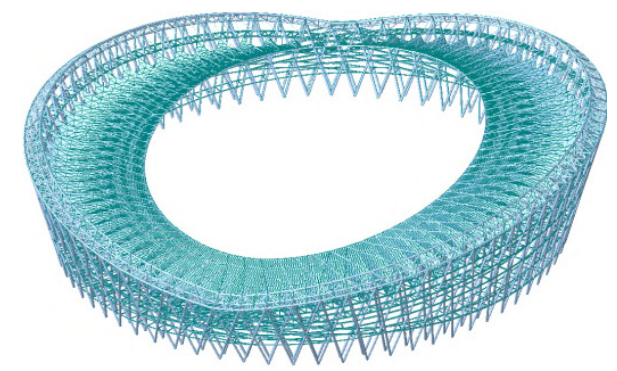

Fig. 1. Saddle-shaped cable suspended

\section{Reliability-BASEd Sensitivity ANALYSis Methods}

\section{A. Sensitivity}

Sensitivity analysis is the method to evaluate the structural response rate caused by the change of the design variables or

Manuscript received January 31, 2013; revised May 6, 2013.

Zhansheng Liu was with Tianjin University, Tianjin. He is now with the Postdoctoral Scientific Research Workstation, Beijing Construction Engineering Group, Beijing, 100039 China (e-mail: 1zs4216@163.com).

Aiwu Luo is with the Beijing Building Construction Research Institute, Beijing, China (e-mail: bbcrikykf@vip.sina.com). parameters. It plays an important role in the reliability evaluation of system performance and the research on structural redundancy [3]. Generally the analysis on all kinds of uncertainty factors can be carried through the sensitivity analysis method that is based on Spearman rank correlation coefficient [4].

\section{B. Calculation Steps}

The response surface technology is to use a hyper surface to approximately substitute the relationship between the input and output of the actual complicated structure [5], [6]. The specific steps of method in this paper:

1) Deterministic finite element analysis, create analysis file;

2) Define the random input variables and random output variables;

3) Invoke finite element program and solve the equations, getting the fitting expression of failure function and solving the undetermined coefficient;

4) Through the response surface test design, conduct the regression analysis to determine the composition item and coefficient of response surface equation;

5) Use the response surface equation to instead the finite element model, based on the Spearman rank correlation coefficient, then carry out the sensitivity analysis.

\section{ENGINEERING EXAMPLES}

\section{A. Calculation Model}

The cover system of the stadium of PanJin belongs to the large-span saddle-shaped cable structure; its building plane has a shape of elliptic ring, with maximum size of about 267 meters in the long axis direction, and 234 meters in the short. The main cable system consists of one inner ring cable and several radial cables, including 144 lifting cables, 72 notochord cables and 72 rope valley cables. The overall ANSYS finite element calculation model is shown in Fig. 2.

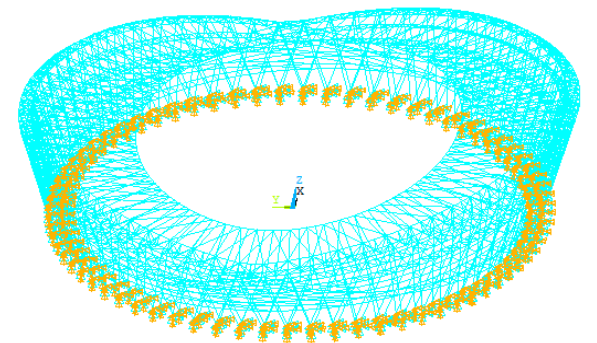

Fig. 2. Panjin stadium integral finite element calculation model

\section{B. Statistical Parameter Selection}

To ensure certain reliability of the structure design, the parameters, such as the load value, material strength value, 
component size and so on, are all standard value that meets a certain standard of reliability. In order to conduct the reliability analysis, it is necessary to know the real distribution of these parameters, or according to statistics experience, work out their relationship. The statistical parameters [7] of random variables used in this example, such as the material properties and section size and so on are shown in table I.

TABLE I: THE STATISTICAL PARAMETERS OF RANDOM VARIABLES

\begin{tabular}{|c|c|c|c|c|}
\hline Number & $\begin{array}{l}\text { Random } \\
\text { variables }\end{array}$ & $\begin{array}{c}\text { Distribution } \\
\text { pattern }\end{array}$ & $\begin{array}{c}\text { Average } \\
\text { value }\end{array}$ & $\begin{array}{l}\text { Coefficient } \\
\text { of variability }\end{array}$ \\
\hline E1 & $\begin{array}{c}\text { Radial cable } \\
\text { elastic } \\
\text { modulus } \\
\end{array}$ & $\begin{array}{c}\text { Normal } \\
\text { distribution }\end{array}$ & $1.56 \mathrm{e} 11 \mathrm{~N} / \mathrm{m}^{2}$ & 0.06 \\
\hline E11 & $\begin{array}{l}\text { Ring cable } \\
\text { elastic } \\
\text { modulus } \\
\end{array}$ & $\begin{array}{c}\text { Normal } \\
\text { distribution }\end{array}$ & $1.65 \mathrm{e} 11 \mathrm{~N} / \mathrm{m}^{2}$ & 0.06 \\
\hline Dens11 & Cable density & $\begin{array}{c}\text { Normal } \\
\text { distribution }\end{array}$ & $9000 \mathrm{~kg} / \mathrm{m}^{3}$ & 0.05 \\
\hline FYN & $\begin{array}{l}\text { Ultimate } \\
\text { tensile } \\
\text { strength of } \\
\text { ring cable } \\
\end{array}$ & $\begin{array}{l}\text { Lognormal } \\
\text { distribution }\end{array}$ & $1670 \mathrm{Mpa}$ & 0.07 \\
\hline FYD & $\begin{array}{c}\text { Ultimate } \\
\text { tensile } \\
\text { strength of } \\
\text { radial cable } \\
\end{array}$ & $\begin{array}{l}\text { Lognormal } \\
\text { distribution }\end{array}$ & $1670 \mathrm{Mpa}$ & 0.08 \\
\hline uhuo & Live load & $\begin{array}{c}\text { Extreme I } \\
\text { type }\end{array}$ & $0.45 \mathrm{kN} / \mathrm{m}^{2}$ & 0.288 \\
\hline ANS & $\begin{array}{c}\text { Inner ring } \\
\text { cable } \\
\text { sectional area } \\
\end{array}$ & $\begin{array}{l}\text { Lognormal } \\
\text { distribution }\end{array}$ & $0.00830 \mathrm{~m}^{2}$ & 0.05 \\
\hline AJS1 & $\begin{array}{c}\text { Ridge cable } \\
\text { sectional area }\end{array}$ & $\begin{array}{l}\text { Lognormal } \\
\text { distribution }\end{array}$ & $0.00249 \mathrm{~m}^{2}$ & 0.05 \\
\hline AGS1 & $\begin{array}{l}\text { Valley cable } \\
\text { sectional area }\end{array}$ & $\begin{array}{l}\text { Lognormal } \\
\text { distribution }\end{array}$ & $0.00332 \mathrm{~m}^{2}$ & 0.05 \\
\hline ADS1 & $\begin{array}{l}\text { Lifting cable } \\
\text { sectional area }\end{array}$ & $\begin{array}{l}\text { Lognormal } \\
\text { distribution }\end{array}$ & $0.00634 \mathrm{~m}^{2}$ & 0.05 \\
\hline Pre & $\begin{array}{c}\text { Inner ring } \\
\text { cable } \\
\text { prestress } \\
\end{array}$ & $\begin{array}{l}\text { Normal } \\
\text { distribution }\end{array}$ & $277.27 \mathrm{Mpa}$ & 0.288 \\
\hline Prej & $\begin{array}{c}\text { Ridge cable } \\
\text { prestress }\end{array}$ & $\begin{array}{l}\text { Normal } \\
\text { distribution }\end{array}$ & $277.27 \mathrm{Mpa}$ & 0.288 \\
\hline Preg & $\begin{array}{c}\text { Valley cable } \\
\text { prestress }\end{array}$ & $\begin{array}{l}\text { Normal } \\
\text { distribution }\end{array}$ & $277.27 \mathrm{Mpa}$ & 0.288 \\
\hline Pred & $\begin{array}{l}\text { Lifting cable } \\
\text { prestress }\end{array}$ & $\begin{array}{l}\text { Normal } \\
\text { distribution }\end{array}$ & $277.27 \mathrm{Mpa}$ & 0.288 \\
\hline
\end{tabular}

\section{SENSITIVITY ANALYSIS RESEARCH}

According to the above method and the sensitivity analysis methods that based on Sperman rank correlation coefficient, use the secondary development platform provided by ANSYS, formulate corresponding APDL calculation procedure, and conduct relative calculation. Carry out the response surface fitting and the sensitivity analysis of related parameters of the string support network shell, choosing the load condition as 1.2DL + 1.4LL + PRL.

\section{A. Response Surface Fitting}

According to the response surface method, the sample value of maximum displacement (DMAX) and inner ring line intensity (NSQ) of the string support network shell was shown in Fig. 3 and Fig. 4, the column graph of output parameters DMAX and NSQ was shown in Fig. 5 and Fig. 6 , the response surface of the maximum displacement (DMAX) and inner ring cable stress (SAXL) was shown in Fig. 7 and Fig. 8 .

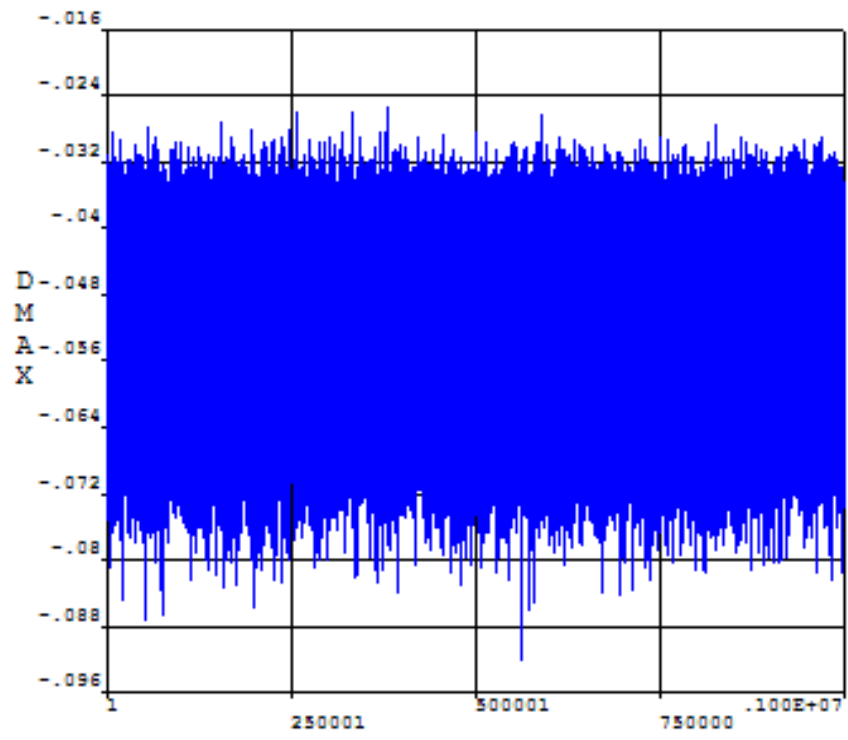

Fig. 3. Sampled Values for DMAX

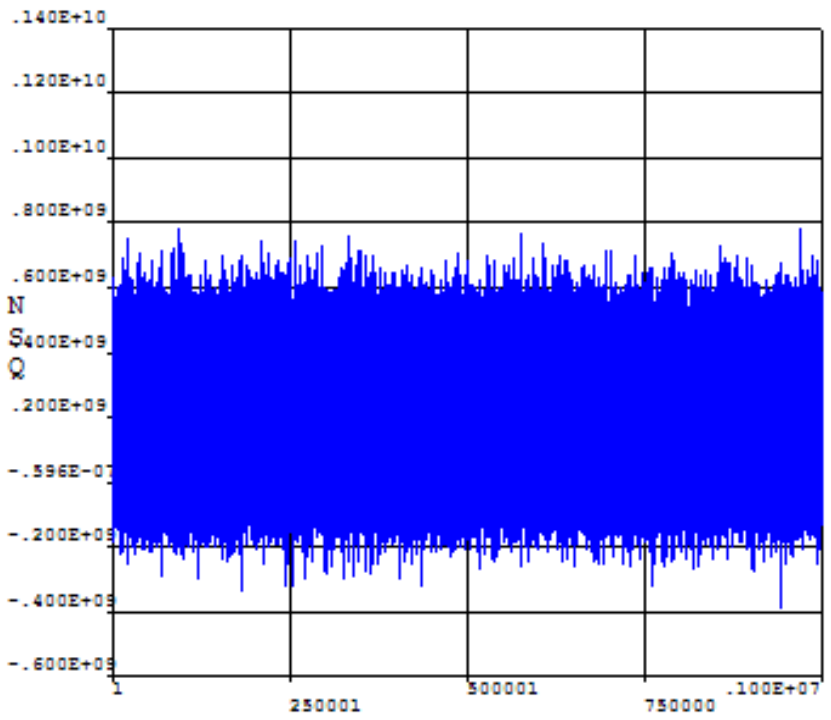

Fig. 4. Sampled Values for NSQ

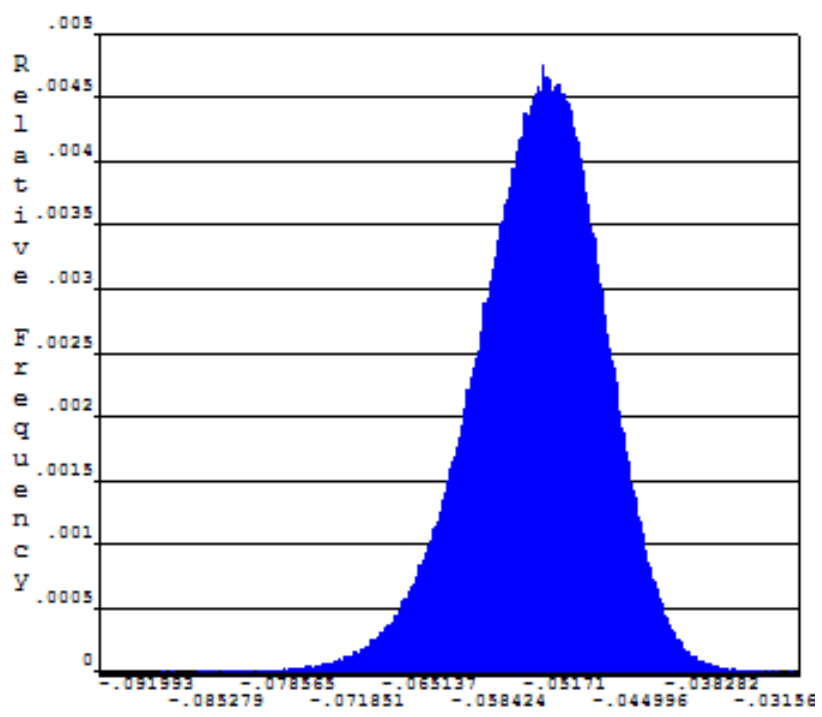

Fig. 5. Histogram of DMAX 


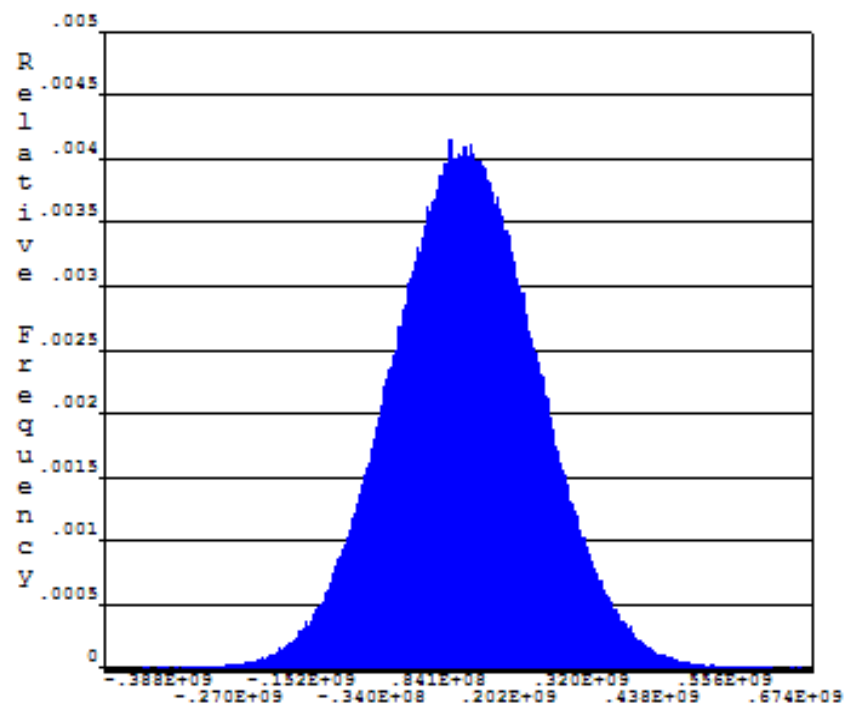

Fig. 6. Histogram of NSQ

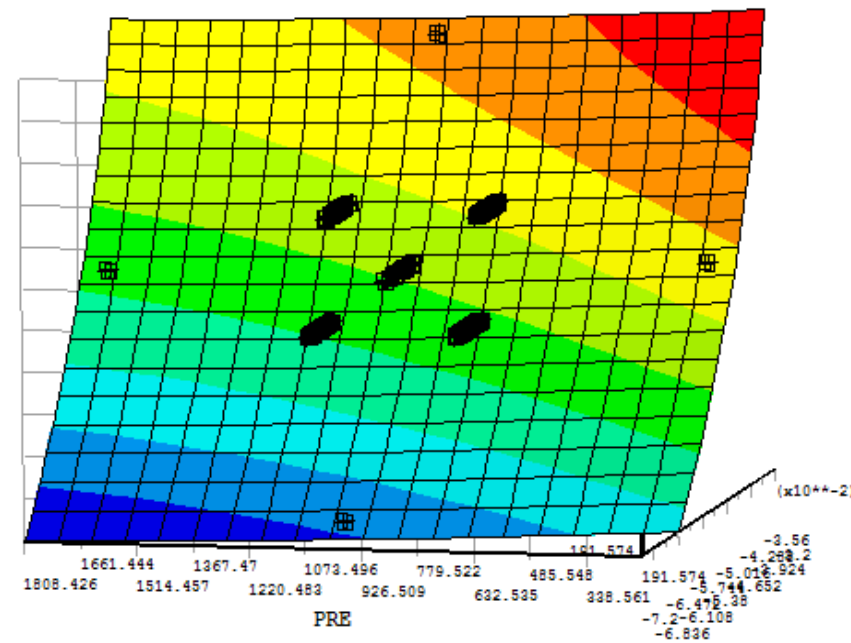

Fig. 7. Response surface of DMAX

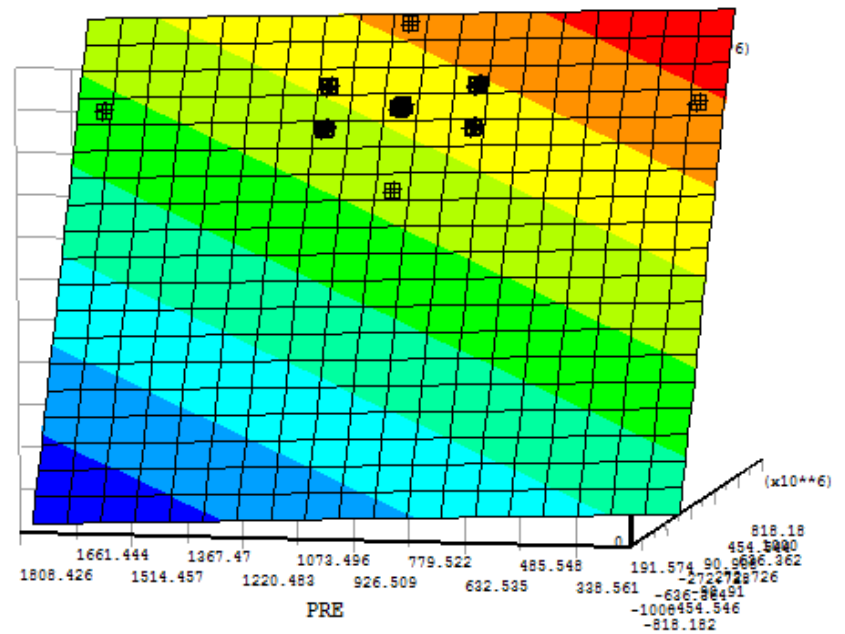

Fig. 8. Response surface of SAXL

As is shown in the sample history in Fig. 3 and Fig. 4, the mean and standard deviation of DMAX and NSQ is gradually convergent and the convergence curve tends to be level, with confidence boundary range meeting sampling requirements. As is shown in figure 5 and figure 6 , the histogram curve of DMAX and NSQ is close to the probability function curve, smooth and with no big gap and visible cycle times enough to meet the requirements of the response surface analysis method. As is shown in Fig. 7 and Fig. 8, fitting equation is reasonable, meeting the requirements of the probability analysis.

\section{B. Sensitivity Coefficient}

The sensitivity size of the basic random variables to structural maximum displacement DMAX is shown in Fig. 9, the sensitivity size of the basic random variables to lifting cable stress DSQ is shown in Fig. 10.

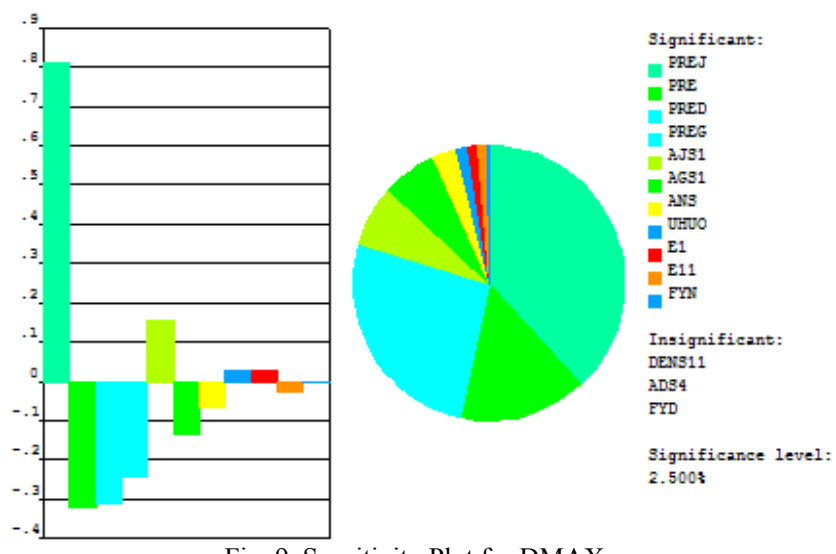

Fig. 9. Sensitivity Plot for DMAX

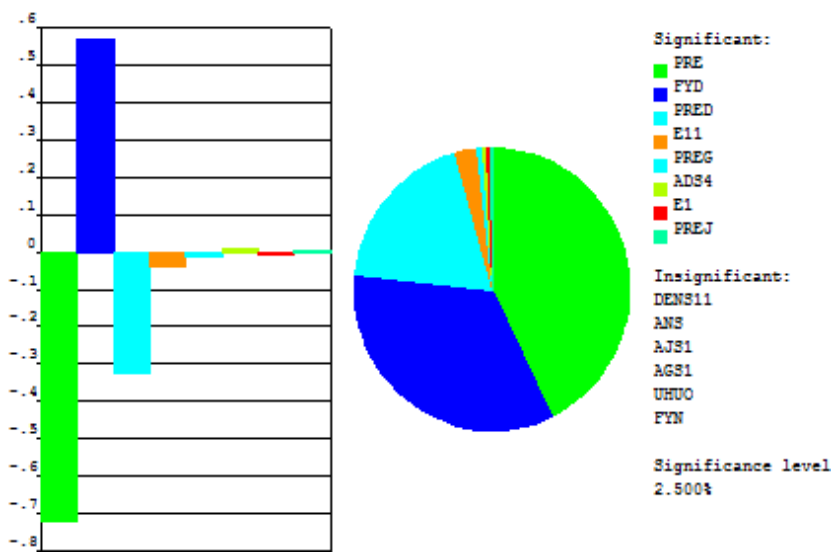

Fig. 10. Sensitivity Plot for DSQ

It is can be seen in Fig. 9 that the sensitivity of the largest displacement by different parameters differs greatly, of which the sensitivity of ridge prestress (PREJ) is the largest, the second is the inner ring cable prestress (PRE), lifting cable prestress (PRED), valley cable prestress (PREG) and the sectional area of ridge cable (AJS1), valley cable (AGS1) and inner ring cable (ANS), while the sensitivity of other parameters is smaller. It is can be seen in figure 10 that the sensitivity of the lifting cable stress by inner ring cable prestress (PRE) is the largest, the second is the ultimate tensile strength of the lifting cable (FYD), lifting cable prestress (PRED), elastic modulus of the inner ring cable (E11), valley cable prestress (PREG) and the sectional area of lifting cable (ADS1), while the sensitivity of other parameters is smaller.

\section{CONCLUSIONS}

In this paper, the structure sensitivity analysis was conducted taking into account the characteristics of 
saddle-shaped cables suspended and the sensitivity coefficient of the main parameters was obtained. According to the results of analysis, the conclusions follow:

1) The response surface analysis method probability-based can properly analyze the sensitivity of the design parameters of cable-suspended structure and provide reference for the similar structure analysis.

2) The sensitivity of different design parameters can reflect its importance to the mechanics performance of saddle-shaped cables suspended, so that it can be controlled in the design and construction to meet the requirements of codes, and make the structure reasonable and reliable.

3) The probability-based design thought of "on a performance basis" is the trend of the development of today's standard, how to promote the reliability theory in the application of prestressed structure design is also very important, so as to provide more sufficient scientific basis for the popularization of new prestressed structure.

\section{ACKNOWLEDGEMENTS}

The author Dr. Zhansheng Liu thanks the financial support of "Project supported by Beijing Postdoctoral Research Foundation (2012ZZ-107)".

\section{REFERENCES}

[1] Z. H. Chen, Z. S. Liu, and W. T. Qiao, "Mechanical characteristics and reliable performance of cable supported barrel vault structure under different limit states," Journal of Tianjin University, pp. 1037-1044, December 2010.

[2] Z. S. Liu and Z. H. Chen, "Reliability analysis of prestressed steel structure in regards to temperature action," Advanced Materials Research, vols. 97-101, pp. 4415-4419.

[3] C. M. Liu and X. L. Liu, "Stiffness-based evaluation of component importance and its relationship with redundancy," Journal of Shanghai Jiaotong University, 2005, vol. 39, no. 5, pp.746- 750.

[4] S. Kamet and Z. Kokuruduva, "Nonlinear analytical solution for cable truss," Journal of Engineering Mechanics, ASCE' 2006, vol. 132, no. 1, pp. 119-123.

[5] R. C. Soares, A. Mohamed, and W. S. Venturini, "Reliability analysis of non-linear reinforced concrete frames using the response surface method," Reliability Engineering and System Safety, 2002, vol. 75, pp. $1-16$.

[6] J. Cheng and Q. S. Li, "Application of the response surface methods to solve inverse reliability problems with implicit response functions," Computational Mechanics, 2009, vol. 43, no. 4, pp. 451-459.

[7] Unified Standard for Reliability Design of Building Structures, GB50068-2001 (in Chinese).

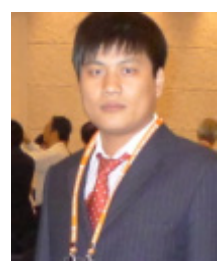

Zhansheng Liu was born in Puyang City, Henan Province, in 1983. He graduated from Dept. Civil Engineering, Tianjin University, Tianjin, CHINA. His main field is prestressed structure and Reliability analysis. 